\title{
ANALYSIS OF THERMAL LOSSES IN AIR-WATER INTERFACIAL SOLAR HEATING SYSTEMS
}

\author{
Shuzhe Wang, Paul G. O’Brien \\ Department of Mechanical Engineering \\ Lassonde School of Engineering, York University \\ Toronto, Canada \\ szwang94212@gmail.com
}

\begin{abstract}
This paper reports a numerical analysis of solardriven seawater desalination systems with two configurations: a floating photo-thermal film at the air-water interface with and without an insulation layer located beneath its surface. Heat transfer processes from the film including conduction, convection and radiation have been evaluated at different film temperatures to determine the relative contributions of different heat loss mechanisms from the film. Convective heat transferred to the bulk seawater is found to be the dominant heat loss path, and can be reduced from $6.95 \times 10^{7} \mathrm{~J} / \mathrm{m}^{2} \cdot \mathrm{h}$ to $8.77 \times$ $10^{5} \mathrm{~J} / \mathrm{m}^{2} \cdot \mathrm{h}$, a difference of almost two orders of magnitude, by inserting an insulation layer beneath the photo-thermal film. Thus, the addition of an insulating layer is suggested as an important design component to effectively minimize heat losses in air-water interfacial solar heating systems.
\end{abstract}

Keywords-solar interfacial heating; desalination; heat transfer

\section{INTRODUCTION}

Worldwide freshwater scarcity has been a longstanding issue due to the demands of an ever-growing population. In addition to environmental conservation, freshwater production is an important solution for meeting this urgent need. Seawater covers most of the earth's surface, and is considered to be a sustainable source of continuous freshwater supply. However, the predominant methods used to desalinate seawater, such as multistage flash distillation (MSF) and reverse osmosis (RO), typically consume $5 \sim 26$ times as much energy as the latent heat of water (about $2400 \mathrm{~kJ} / \mathrm{kg}$ ) [1], [2]. A promising alternative approach is solar-driven seawater desalination, whereby heat generated from the solar irradiance is used to evaporate water, which minimizes the need for fossil fuels and electric power. However, traditional solar-driven water desalination systems exhibit low efficiencies (typically 34 - 40\% for a single basin solar still [3]) due to large heat losses to the bulk water reservoir.

To improve solar distillation systems, numerous photothermal materials with different morphologies and surface properties have been investigated for their performance of absorbing solar irradiance and producing heat to enhance evaporation. In this regard, plasmon resonance phenomena in metallic materials, such as $\mathrm{Au}$ [4], [5], Ag [6] and $\mathrm{Cu}$ [7], [8], have been investigated in terms of light absorption and localized heat generation for accelerated water evaporation. For example, Jin et al. achieved a the solar-thermal conversion efficiency (the ratio of the thermal energy used for evaporation and the total incident solar irradiance) of $80.3 \%$ using $\mathrm{Au}$ nanoparticles dispersions under 220 sun illumination $\left(1\right.$ sun $\approx 1 \mathrm{~kW} / \mathrm{m}^{2}$ ) [4]. Besides, carbon-based materials such as graphene and reduced graphene oxide have gained popularity for solar-driven distillation applications in the past few decades on account of their excellent photo-thermal properties. Y. Ito et al. found that nitrogen doped nano-porous graphene sheets floating on the airwater interface were heated to $100{ }^{\circ} \mathrm{C}$ under concentrated solar irradiation while the bulk water remained at $35^{\circ} \mathrm{C}$, reaching an $80 \%$ conversion efficiency of received solar radiation to the latent heat of water [9]. This strategy of using a photo-thermal film located at the air-water interface has promising potential to increase the efficiency of solar desalination systems because heat generated from the absorbed solar energy is localized at the air-water interface where the evaporation process occurs.

To date, simulations and mathematical analysis of heat and mass transfer in traditional solar distillation plants [10]-[13] and molecular dynamic modeling for general evaporation [14], [15] have been reported in the literature. However, few studies have investigated heat loss mechanisms in photo-thermal films used for air-water interfacial solar heating from a heat transfer perspective to seek quantitative explanations for their superior performance. Herein, numerical analysis is performed to investigate the performance of two air-water interfacial solar heating configurations, wherein 1) a thin film of black photothermal material (e.g. graphene and its derivatives) floats directly on the air-water interface, and 2) the film structure is similar to the first configuration but with a thermal-insulation layer inserted between the photo-thermal film and the bulk water. Simplified models are used to study the convective, conductive and radiative heat transfer losses from the photothermal film to its surrounding environment. Comparisons between these heat losses and the energy contributed to evaporate water are made in order to provide recommendations for optimizing the design of solar-driven water desalination systems. 


\section{MATHEMATICAL MODEL AND ANALYSIS}

\section{A. General Assumptions}

Herein we model two air-water interfacial solar heating configurations, namely 1) floating photo-thermal film without an insulation layer and 2) floating photo-thermal film with an insulation layer. In practice, the photo-thermal film has a thickness at the micron scale and exhibits high absorptivity towards solar irradiance such that its temperature is sufficiently increased to provide thermal energy to facilitate the water evaporation process. In this work, to simplify the heat transfer analysis, it is assumed that the solar irradiance heats the film isothermally to a constant temperature $T_{f}$, which is reasonable considering the high thermal conductivity and small thickness of the film. Furthermore, in practice the photo-thermal film would be porous to allow for vapour to escape from the reservoir. However, an assumption is made that the photo-thermal film is flat on both its upper and lower surfaces and has zero thickness for simplification. Also, small turbulence induced by mass transfer (replenishment) from the bulk to the heat-up zone below the film is not considered. Moreover, the analysis presented herein assumes a one-dimensional, quasi-steady state case, and horizontal heat diffusion along the planar direction of the film is not considered. It is also assumed that the thermal properties of the film are independent of temperature and its heat capacity is negligible. The air is quiescent and remains at constant temperature, $T_{a}$, at distances far above the photo-thermal film. Both the air and water vapor behave as ideal gases. It is assumed that sidewalls of the tank are thermal-insulated without edge effects and the temperature of the water far beneath the air-water interface is at a constant value, $T_{w 0}$. The parameters considered in the analysis as well as the dimensions and related physical properties are provided in Table I.

\section{B. Floating Photo-Thermal Film without an Insulation Layer}

In this model the photo-thermal film floats on the air-water interface and is in direct contact with the water (as shown in Fig. 1 (a) and Fig. 1 (b)). A thermal resistance network for the heat transferred from the photo-thermal film is provided in Fig. 1 (c). This thermal resistance network is consistent with the assumption that evaporation takes place in an ultra-thin layer at the air-water interface where the porous photo-thermal film (with zero thickness) resides. Except for evaporating water, heat is lost from the photo-thermal film due to convection to the air, $Q_{v a}$, radiation to the air, $Q_{r a}$, convection to the bulk water, $Q_{v w}$, and radiation to the bulk water $Q_{r w}$. The surface area of the film, $\mathrm{A}$, is assumed to be $0.3 \mathrm{~m} \times 0.3 \mathrm{~m}$.

Convective heat losses are through natural convection mainly, and are calculated using Newton's Law of cooling:

$$
\begin{gathered}
Q_{v a}=A \overline{h_{a}}\left(T_{f}-T_{a}\right) \\
Q_{v w}=A \overline{h_{w}}\left(T_{f}-T_{w 0}\right)
\end{gathered}
$$

where $\overline{h_{a}}$ and $\overline{h_{w}}$ are the heat transfer coefficients for convection to the air and water, respectively, and are determined by the following empirical correlations:

$$
\begin{gathered}
R a_{L}=\frac{g \beta \Delta T L_{C}{ }^{3}}{\alpha \gamma} \\
\overline{N u_{L}}=\left\{\begin{array}{l}
0.54 R a_{L}^{1 / 4}\left(\text { upper surface } 10^{7} \leq R a_{L} \leq 10^{11}\right) \\
0.27 R a_{L}{ }^{1 / 4}\left(\text { lower surface } 10^{5} \leq R a_{L} \leq 10^{10}\right)
\end{array}\right. \\
\bar{h}=\frac{k \overline{N u_{L}}}{L_{C}}
\end{gathered}
$$

where $\Delta T$ is the relevant temperature difference.

Radiative heat transfer losses are determined using the Stefan-Boltzmann Law:

$$
\begin{gathered}
Q_{r a}=A \varepsilon \sigma\left({T_{f}}^{4}-T_{a}^{4}\right) \\
Q_{r w}=A \varepsilon \sigma\left(T_{f}^{4}-T_{w 0}^{4}\right)
\end{gathered}
$$

Thermal energy transferred from the film for evaporation consists of both the sensible and latent heat of water, and is given by the following formula:

$$
Q_{\text {evap }}=A \dot{m}\left[\Delta H+C\left(T_{f}-T_{w 0}\right)\right]
$$

The temperature of the vapor is assumed to be the same as that of the film, so the sensible heat for a rise of water temperature from the initial temperature $T_{w 0}$ to $T_{f}$ is included in the calculation for $Q_{\text {evap }}$. Methods used to determine the evaporation rate, $\dot{m}$, are discussed in Section III with reference to Fig. 3.
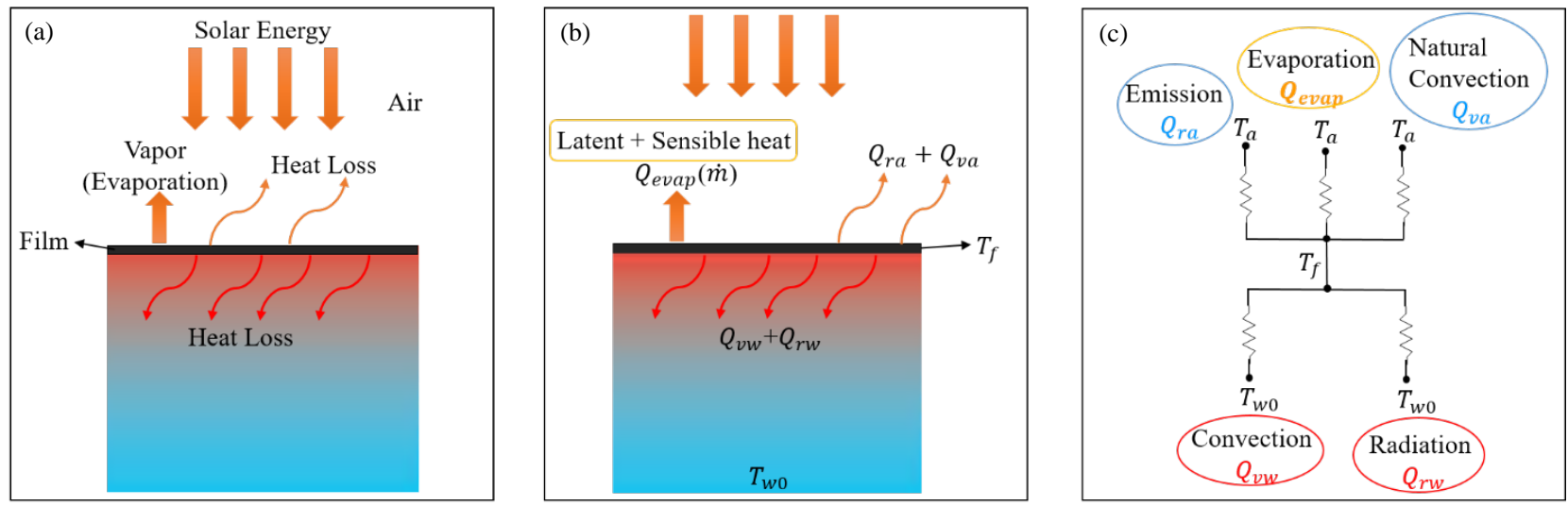

Figure 1. (a) (b) Simplified heat transfer model for a solar interfacial heating model using a floating photo-thermal film. (c) Thermal resistance network for the floating photo-thermal film. 

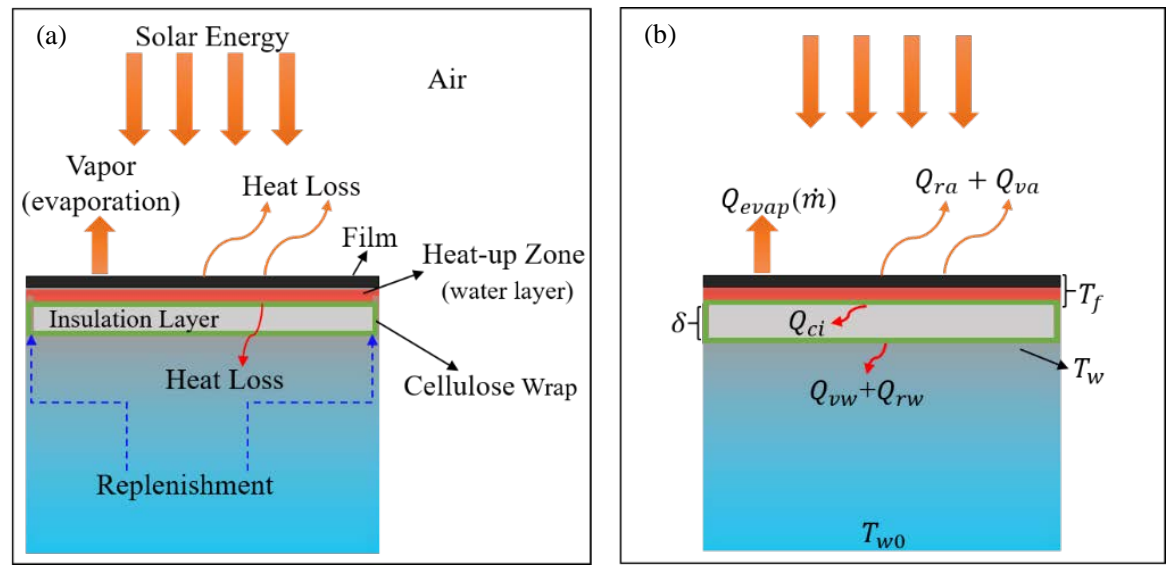

Figure 2. (a) (b) Simplified heat transfer model for solar interfacial heating model using photo-thermal film with an insulation layer underneath.

\section{Floating Photo-Thermal Film with an Insulation Layer}

In the second air-water interfacial solar heating configuration, an insulation layer (such as cellular glass or polystyrene foam with a low thermal conductivity of about 0.05 $\mathrm{W} / \mathrm{m} \cdot \mathrm{K}$ ) with a thickness of $\delta$ is inserted below the photothermal film to reduce convective loss to the bulk water (Fig. 2 (a) and Fig. 2 (b)).

In this configuration, a structure similar to that of a cellulose wrap [16] is applied for replenishment during evaporation, i.e. water is driven by capillary forces from the bulk. A thin water layer (with a thickness of $\sim 0.1 \mathrm{~mm}$ ), herein referred to as the "heat-up zone" in Fig. 2 (a), is thus created and resides on top of the insulating layer, right below the photo-thermal film. It is assumed that the temperature of the heat-up zone is equal to that of the film, $T_{f}$. The amount of thermal energy transferred from the film downwards through the insulator is equal to the sum of the convective and radiative heat losses from the bottom of the insulation layer to the bulk water:

$$
Q_{c i}=Q_{v w}+Q_{r w}
$$

Thus, it is assumed that the total heat loss from the photo-thermal film is the sum of three heat loss mechanisms: radiation and convection to the air, and conduction to the insulator. Equation
(1) - (7) are used again to determine the heat losses in the second configuration, except the temperature at the insulating layerbulk water interface, $T_{w}$, is used to calculate the radiative and convective heat losses to the water. $T_{w}$ is determined using (9). Conduction through the insulator is given by the following equation:

$$
Q_{c i}=\frac{\mathrm{A} k_{i}\left(T_{f}-T_{w}\right)}{\delta}
$$

where $k_{i}$ is the thermal conductivity of the insulator.

\section{RESULTS AND DISCUSSION}

To determine the evaporation rate at the air-water interface as a function of the photo-thermal film temperature, $T_{f}$, an empirical relationship has been determined using experimental data reported in the literature [17]-[21]. That is, based on evaporation rates reported for air-water interfacial solar heating employing various photo-thermal sheet-like carbon materials such as graphene, rGO (reduced graphene oxide) and graphite, an exponential curve fitting for the evaporation rate has been applied and the results are shown in Fig. 3 (a). The evaporation rates achieved are between $0.92 \mathrm{~kg} / \mathrm{m}^{2} \cdot \mathrm{h}$ and $3.5 \mathrm{~kg} / \mathrm{m}^{2} \cdot \mathrm{h}$ in most studies.
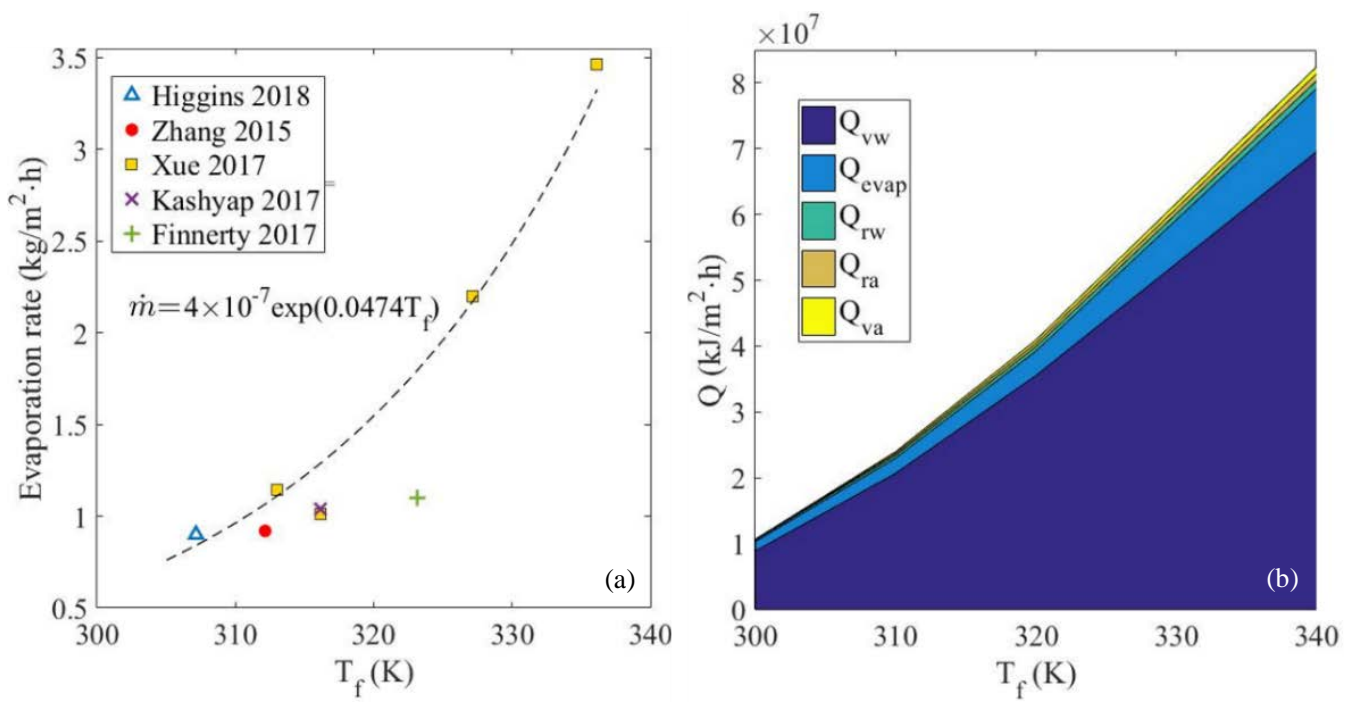

Figure 3. (a) Exponential fitting of the data from previous work $\left(R^{2}=0.8415\right)$ [17]-[21]. (b) Thermal energy transferred from the photo-thermal film due to water evaporation, convection and radiation to the water, and convection and radiation to ambient air in the floating film without an insulation layer configuration. 
For the first configuration, floating photo-thermal film without an insulation layer, thermal energy transferred through the different paths are plotted in Fig. 3 (b). Every heat transfer pathway steadily increases with increasing $T_{f}$, as the temperature difference between the photo-thermal film and its surrounding environment increases. When the photo-thermal film is at a temperature of $340 \mathrm{~K}$, the amount of energy used to evaporate water $\left(Q_{\text {evap }}\right)$ is $\sim 9.6 \times 10^{6} \mathrm{~J} / \mathrm{m}^{2} \cdot \mathrm{h}$, whereas the convective loss to the bulk water, $Q_{v w}$, is almost 7 times larger than $Q_{\text {evap }}$, and dominates over other heat transfer processes. Thus, natural convection to the bulk water is the major heat loss mechanism, limiting the efficiency of air-water interfacial solar heating evaporation systems. It can be noted that the sum of the heat lost to the air $\left(Q_{r a}\right.$ and $\left.Q_{v a}\right)$ and radiation to the bulk water $\left(Q_{r w}\right)$ is only $4 \%$.

The effectiveness of placing an insulation layer beneath the photo-thermal film to mitigate convective heat losses from the film to the bulk water is analyzed in the second configuration, floating photo-thermal film with an insulation layer. The results show the addition of an insulating layer significantly alters the thermal energy loss distribution. As shown in Fig. 4 (a), for an insulating layer with a thickness of $0.001 \mathrm{~m}$, the convective heat $Q_{v w}$ is reduced dramatically because the thermal insulation layer reduces the heat transfer lost from the photo-thermal film to the underlying bulk water. For example, for a photo-thermal film temperature of $T_{f}=340 \mathrm{~K}, Q_{v w}=8.77 \times 10^{5} \mathrm{~J} / \mathrm{m}^{2} \cdot \mathrm{h}$, which is just $1.26 \%$ of its former value of $6.95 \times 10^{7} \mathrm{~J} / \mathrm{m}^{2} \cdot \mathrm{h}$ for the configuration where the insulating layer is absent. Consequently, the percentage of heat used in evaporating water, $Q_{\text {evap }}$, increases from $11 \%$ to $76 \%$ of the total energy transferred from the photo-thermal film. Moreover, the influence of the insulator layer thickness on $Q_{v w}$ is also shown in Fig. 4 (b). As the thickness of the insulating layer increases the convective heat transfer losses to the bulk water are further decreased. For the thickest insulator layer considered in this study, $\delta=0.1 \mathrm{~m}$, convective loss to the bulk water decreases below $9000 \mathrm{~J} / \mathrm{m}^{2} \cdot \mathrm{h}$, which is even lower than $Q_{r a}$ and $Q_{v a}$ when $300 \mathrm{~K}<T_{f}<340$ $\mathrm{K}$. Thermal energy dissipations to the air, namely $Q_{r a}$ and $Q_{v a}$,

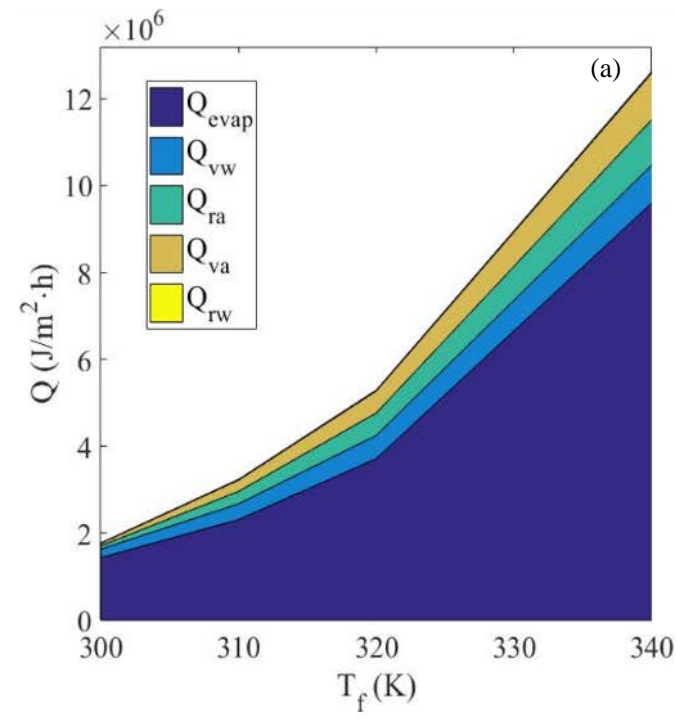

stay unchanged because they only depend on $T_{f}$ and $T_{a}$, regardless of the presence of an insulation layer under the film.

In conclusion, numerical analysis of the thermal energy losses in air-water interfacial solar heating systems shows that convection to the bulk water is the dominant loss mechanism, wasting up to over $80 \%$ of the available thermal energy. To improve the overall performance of interfacial air-water solar desalination systems, the application of an insulation layer beneath the photo-thermal film is recommended to effectively supress heat losses to the bulk of the reservoir.

TABLE I. PARAmeters AND Photo-Thermal Film Dimensions

\begin{tabular}{|c|c|c|c|}
\hline \multicolumn{4}{|c|}{ Nomenclature } \\
\hline$T_{f}$ & $\begin{array}{l}\text { Temperature of the photo- } \\
\text { thermal film }\end{array}$ & $\sigma$ & $\begin{array}{l}\text { Stefan-Boltzmann } \\
\text { constant }\left(\mathrm{W} / \mathrm{m}^{2} \cdot \mathrm{K}^{4}\right)\end{array}$ \\
\hline$T_{a}$ & $\begin{array}{l}\text { Temperature of the air (296 } \\
\text { K) }\end{array}$ & $g$ & $\begin{array}{l}\text { Acceleration of gravity } \\
\left(\mathrm{N} / \mathrm{m}^{2} \cdot \mathrm{s}\right)\end{array}$ \\
\hline$T_{w 0}$ & $\begin{array}{l}\text { Initial temperature of the } \\
\text { water }(288 \mathrm{~K})\end{array}$ & $\overline{N u_{L}}$ & Nusselt number \\
\hline$Q_{v a}$ & $\begin{array}{l}\text { Convective heat transfer to } \\
\text { the air }\left(\mathrm{J} / \mathrm{m}^{2} \cdot \mathrm{s}\right)\end{array}$ & $h_{f g}$ & $\begin{array}{l}\text { Latent heat of water } \\
(\mathrm{kJ} / \mathrm{kg})\end{array}$ \\
\hline$Q_{v w}$ & $\begin{array}{l}\text { Convective heat transfer to } \\
\text { the bulk water }\left(\mathrm{J} / \mathrm{m}^{2} \cdot \mathrm{s}\right)\end{array}$ & $\varepsilon$ & $\begin{array}{l}\text { Emissivity of the film }(\approx \\
0.9)\end{array}$ \\
\hline$Q_{r a}$ & $\begin{array}{l}\text { Radiative heat transfer to the } \\
\text { air }\left(\mathrm{J} / \mathrm{m}^{2} \cdot \mathrm{s}\right)\end{array}$ & $\beta$ & $\begin{array}{l}\text { Volume thermal } \\
\text { expansion coefficient } \\
\text { (/K) }\end{array}$ \\
\hline$Q_{r w}$ & $\begin{array}{l}\text { Radiative heat transfer to the } \\
\text { bulk water }\left(\mathrm{J} / \mathrm{m}^{2} \cdot \mathrm{s}\right)\end{array}$ & $\alpha$ & $\begin{array}{l}\text { Thermal diffusivity } \\
\left(\mathrm{m}^{2} / \mathrm{s}\right)\end{array}$ \\
\hline$Q_{c i}$ & $\begin{array}{l}\text { Conductive heat transfer to } \\
\text { the insulation layer }\left(\mathrm{J} / \mathrm{m}^{2} \cdot \mathrm{s}\right)\end{array}$ & $\gamma$ & Kinetic viscosity (m²/s) \\
\hline$\delta$ & $\begin{array}{l}\text { Thickness of the insulation } \\
\text { layer (m) }\end{array}$ & $\dot{m}$ & $\begin{array}{l}\text { Evaporation rate or vapor } \\
\text { flux close to film surface } \\
\text { in the air }\left(\mathrm{kg} / \mathrm{m}^{2} \cdot \mathrm{h}\right)\end{array}$ \\
\hline$L_{c}$ & $\begin{array}{l}\text { Characteristic length of the } \\
\text { film (A/Perimeter }=0.075 \mathrm{~m})\end{array}$ & $\mathrm{k}$ & $\begin{array}{l}\text { Thermal conductivity } \\
(\mathrm{W} / \mathrm{m} \cdot \mathrm{K})\end{array}$ \\
\hline$R a_{L}$ & Rayleigh number & $C$ & $\begin{array}{l}\text { Specific heat capacity of } \\
\text { water }(\mathrm{kJ} / \mathrm{kg} \cdot \mathrm{K})\end{array}$ \\
\hline
\end{tabular}

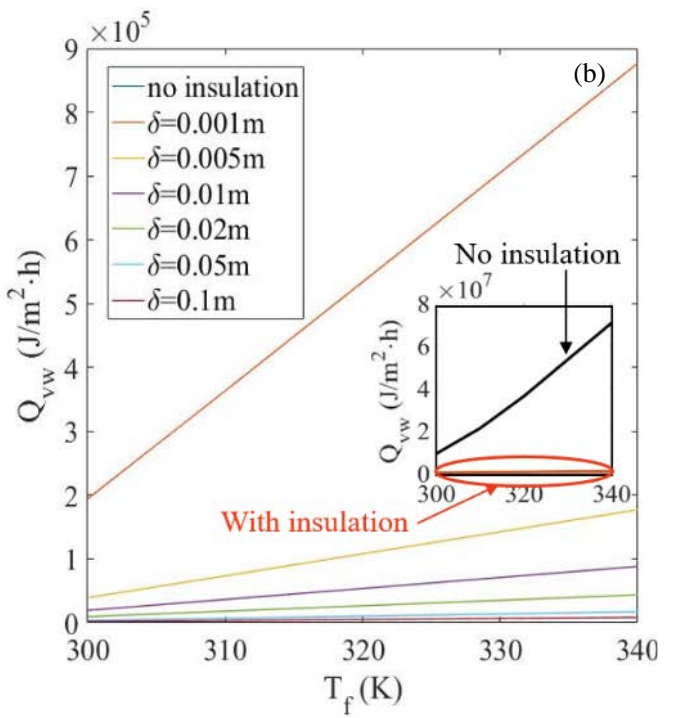

Figure 4. (a) Thermal energy transfer from the photo-thermal film as a function of its temperature due to water evaporation, convection and radiation to the water, and convection and radiation to the ambient air for the configuration with an insulating layer ( $\delta=0.001 \mathrm{~m}$ ). (b) Convective heat losses to the bulk water as a function of the photo-thermal film temperature for different thicknesses, $\delta$, of the insulating layer situated beneath the film. The inset shows that convective losses to the bulk water for the configuration with an insulation layer is almost two orders of magnitude less than that of the configuration without an insulation layer. 


\section{ACKNOWLEDGMENT}

This research was supported by the Natural Sciences and Engineering Research Council of Canada.

\section{REFERENCES}

[1] N. P. Cheremisinoff, Handbook of water and wastewater treatment technologies. 2002.

[2] A. Al-Karaghouli and L. L. Kazmerski, "Energy consumption and water production cost of conventional and renewable-energy-powered desalination processes,” Renew. Sustain. Energy Rev., vol. 24, pp. 343356, 2013.

[3] C. L. Ong, W. Escher, S. Paredes, A. S. G. Khalil, and B. Michel, “A novel concept of energy reuse from high concentration photovoltaic thermal (HCPVT) system for desalination,” Desalination, vol. 295, no. June, pp. 70-81, 2012.

[4] H. Jin, G. Lin, L. Bai, A. Zeiny, and D. Wen, "Steam generation in a nanoparticle-based solar receiver,” Nano Energy, vol. 28, pp. 397-406, 2016.

[5] S. Yu et al., "The impact of surface chemistry on the performance of localized solar-driven evaporation system,” Sci. Rep., vol. 5, no. 1, p. 13600, 2015.

[6] G. M. Akselrod et al., "Large-area metasurface perfect absorbers from visible to near-infrared,” Adv. Mater., vol. 27, no. 48, pp. 8028-8034, 2015.

[7] C. Zhang, C. Yan, Z. Xue, W. Yu, Y. Xie, and T. Wang, "Shapecontrolled synthesis of high-quality Cu7S4 nanocrystals for efficient light-induced water evaporation,” Small, no. 38, pp. 5320-5328, 2016.

[8] P. Fan, H. Wu, M. Zhong, H. Zhang, B. Bai, and G. Jin, "Large-scale cauliflower-shaped hierarchical copper nanostructures for efficient photothermal conversion,” Nanoscale, vol. 8, no. August, pp. 1461714624, 2016.

[9] Y. Ito, Y. Tanabe, J. Han, T. Fujita, K. Tanigaki, and M. Chen, "Multifunctional porous graphene for high-efficiency steam generation by heat localization,” Adv. Mater., vol. 27, no. 29, pp. 4302-4307, 2015.

[10] G. N. Tiwari, H. N. Singh, and R. Tripathi, "Present status of solar distillation,” Sol. Energy, vol. 75, no. 5, pp. 367-373, 2003.
[11] Y. H. Zurigat and M. K. Abu-Arabi, "Modelling and performance analysis of a regenerative solar desalination unit,” Appl. Therm. Eng., vol. 24, no. 7, pp. 1061-1072, 2004.

[12] M. K. Phadatare and S. K. Verma, "Influence of water depth on internal heat and mass transfer in a plastic solar still,” Desalination, vol. 217, no. 1-3, pp. 267-275, 2007.

[13] R. Tripathi and G. N. Tiwari, "Desalination effect of water depth on intemal heat and mass transfer for active solar distillation,” Desalination, vol. 173, pp. 187-200, 2005.

[14] G. Nagayama, M. Kawagoe, A. Tokunaga, and T. Tsuruta, "On the evaporation rate of ultra-thin liquid film at the nanostructured surface: A molecular dynamics study,” Int. J. Therm. Sci., vol. 49, no. 1, pp. 59-66, 2010

[15] H. R. Seyf and Y. Zhang, "Effect of nanotextured array of conical features on explosive boiling over a flat substrate: A nonequilibrium molecular dynamics study,” Int. J. Heat Mass Transf., vol. 66, pp. 613-624, 2013.

[16] X. Li et al., "Graphene oxide-based efficient and scalable solar desalination under one sun with a confined 2D water path,” Proc. Natl. Acad. Sci., vol. 113, no. 49, pp. 13953-13958, 2016.

[17] M. W. Higgins, A. R. Shakeel Rahmaan, R. R. Devarapalli, M. V. Shelke, and N. Jha, "Carbon fabric based solar steam generation for waste water treatment,” Sol. Energy, vol. 159, no. December 2017, pp. 800-810, 2018.

[18] L. Zhang, B. Tang, J. Wu, R. Li, and P. Wang, "Hydrophobic light-to-heat conversion membranes with self-healing ability for interfacial solar heating,” Adv. Mater., vol. 27, no. 33, pp. 4889-4894, 2015.

[19] G. Xue et al., "Robust and low-cost flame-treated wood for highperformance solar steam generation,” ACS Appl. Mater. Interfaces, vol. 9, no. 17, pp. 15052-15057, 2017.

[20] V. Kashyap, A. Al-Bayati, S. M. Sajadi, P. Irajizad, S. H. Wang, and H Ghasemi, "Flexible anti-clogging graphite film for scalable solar desalination by heat localization,” J. Mater. Chem. A, pp. 15227-15234, 2017.

[21] C. Finnerty, L. Zhang, D. L. Sedlak, K. L. Nelson, and B. Mi, "Synthetic graphene oxide leaf for solar desalination with zero liquid discharge," Environ. Sci. Technol., vol. 51, no. 20, pp. 11701-11709, 2017. 